\title{
Alginate from Pseudomonas fluorescens and $P$. putida: production and properties
}

\author{
Elena Conti, ${ }^{1,2}$ Antonella Flaibani, ${ }^{3}$ Michael O'Regan ${ }^{2}$ \\ and Ian W. Sutherland'
}

Author for correspondence: Ian W. Sutherland. Tel: +44 31650 5331. Fax: +44 316505392.

e-mail: I.W.Sutherland@castle.ed.ac.uk

\footnotetext{
1 Institute of Cell and Molecular Biology, Edinburgh University, Mayfield Road, Edinburgh EH9 3JH, UK

2 Fidia Advanced Biopolymers, via Ponte della Fabbrica 3/A, 35031 Abano Terme, Italy

3 POLYbios, Area di Ricerca, Padriciano 99, 1-34012 Trieste, Italy
}

\begin{abstract}
The alginate-like polysaccharides synthesized by Pseudomonas fluorescens and Pseudomonas putida have been prepared from batch cultures grown with glucose and fructose as carbon substrates. Despite the different methods of catabolism of the two substrates and synthesis of the alginate precursors, both strains produced polysaccharides which were consistent in their composition of mannuronic and guluronic acids and in the frequency of occurrence of dimers of D-mannuronic acid. All preparations lacked homooligomeric sequences of L-guluronic acid and were highly acetylated (12-21\%). In all the culture conditions tested, polysaccharide production was growthassociated and maximum $M_{\mathrm{r}}$ was obtained after $48 \mathrm{~h}$ growth; older cultures contained material of progressively lower $M_{r}$. This was ascribed to the degradative activity of alginate lyases which were detected intracellularly in both species and are presumably released by cell lysis. At $72 \mathrm{~h}$, alginate from $P$. putida grown on either substrate had an $M_{r}$ of only 34000-38500, whereas the product from $P$. fluorescens grown on fructose had an $M_{r}$ of 300000 and that from glucose-grown cultures an $M_{r}$ of 72000 .
\end{abstract}

Keywords: alginate, Pseudomonas putida, Pseudomonas fuorescens

\section{INTRODUCTION}

Alginic acid is a linear copolymer of $1 \rightarrow 4$-linked $\beta$-Dmannuronic acid and its C-5 epimer $\alpha$-L-guluronic acid. Commercially available alginates are currently isolated from marine algae such as Laminaria and Macrocystis. The rheological and gel-forming properties of alginate which have led to its commercial exploitation depend on the $M_{r}$ and the distribution and relative content of the two monomers along the polymeric chain. The main industrial applications of alginates are as thickeners, stabilizers, gelling agents, emulsifiers, surface-coating agents, synthetic films and fibres (Sutherland, 1991). In the medical and pharmaceutical areas, alginates have been employed for immobilizing living cells, as in the treatment of hormonal diseases in experimental animal models (Lim \& Sun, 1980), to suspend drugs and antibiotics in emulsion preparations, and to manufacture wound dressings with improved healing properties. More recently, alginates of specific composition have been demonstrated to have antitumour activity (Fujihara \& Nagumo, 1992) and to

Abbreviations: EPS, exopolysaccharide; TBA, thiobarbituric acid. elicit the immune response and induce cytokine production from human monocytes (Garner et al., 1990; Otterlei et al., 1991).

Several species of bacteria of the genera Azotobacter and Pseudomonas produce an exopolysaccharide (EPS) which bears strong resemblance to the algal product, except that the molecule is partially acetylated. Thus, the utilization of bacterial strains could be extended to the production of alginate, as has been possible for other polysaccharides of economic importance such as gellan, hyaluronic acid and xanthan, which are obtained through bacterial fermentation. Polymers of microbial origin offer several advantages, including batch-to-batch homogeneity, lack of seasonal variation, and the fact that such features as $M_{\mathrm{r}}$, composition and yield can be partially controlled by altering the culture conditions (Sutherland, 1987; Obika et al., 1993) or by genetic manipulation of the producing strains (Martins \& Sa-Correia, 1991; Gacesa \& Goldberg, 1992).

The alginate production of Pseudomonas aeruginosa has been the subject of intense study, since the production of the polymer appears to play a crucial role in lung infections found in cystic fibrosis patients (Gacesa \& Russell, 1990). 
These studies have revealed valuable information on the genetics and mechanisms of bacterial alginate production (e.g. Martin et al., 1993). The possibility of producing bacterial alginate has also been examined using a number of non-pathogenic micro-organisms (Horan et al., 1981; Sengha et al., 1989). These studies showed that under appropriate conditions of growth, significant levels of alginate could be obtained. However, no detailed characterization of the polymeric product was undertaken. Most studies on bacterial polysaccharide production have been done with species in which no degradation of the product occurs.

In this work, we have studied alginate production in batch culture in strains of Pseudomonas putida and Pseudomonas fluorescens and determined the chemical composition and other characteristics of the polysaccharide produced. Several growth conditions were tested and the EPS obtained was characterized in detail with reference to acetyl content, $M_{\mathrm{r}}$, polydispersity and monomer composition.

\section{METHODS}

Bacterial strains and methods of culture. The alginateproducing strains $P$. putida 1582 and $P$. fluorescens 1586 were selected from a number of strains kindly provided by Dr John Govan, Medical Microbiology Department, Edinburgh University. The bacteria were maintained by weekly subculture on plates of Oxoid Pseudomonas agar. Cultures were grown in a basal medium containing, per litre, $\mathrm{Na}_{2} \mathrm{HPO}_{4}, 10 \mathrm{~g} ; \mathrm{KH}_{2} \mathrm{PO}_{4}$, $3 \mathrm{~g} ; \mathrm{K}_{2} \mathrm{SO}_{4}, 1 \mathrm{~g} ; \mathrm{NaCl}, 1 \mathrm{~g} ; \mathrm{MgSO}_{4} .7 \mathrm{H}_{2} \mathrm{O}, 0.2 \mathrm{~g} ; \mathrm{CaCl}_{2}$, $0.001 \mathrm{~g} ; \mathrm{FeSO}_{4}, 0.0001 \mathrm{~g} ; \mathrm{NH}_{4} \mathrm{Cl}, 2 \mathrm{~g}$; together with $1 \%(\mathrm{w} / \mathrm{v})$ carbon source. Growth was in Erlenmeyer flasks on an orbital shaker at 150 r.p.m. at $30^{\circ} \mathrm{C}$. Modifications to the standard culture conditions are indicated in the Results. Duplicate or triplicate cultures were used for each experiment.

Recovery of EPS and cell pellet. The cells were removed from the culture broth by centrifugation ( $20 \mathrm{~min}, 12000$ r.p.m.) and the EPS was precipitated from the supernatant by addition of 2 vols cold acetone. After $12 \mathrm{~h}$, the supernatant was carefully decanted and the precipitate was redissolved in a small volume of distilled water, dialysed against running tap water for $48 \mathrm{~h}$ and lyophilized. The cell pellet obtained by centrifugation was washed once with distilled water, lyophilized and weighed

Total carbohydrate estimation. The total carbohydrate content of culture supernatants was determined after dialysis, by the method of Dubois et al. (1956) using glucose as standard.

Alginate determination. Alginate was measured by the method of Kennedy \& Bradshaw (1984); the reagent Vantocil was a gift from ICI. The assay was performed on samples of culture supernatants taken throughout growth and aqueous solutions prepared from the lyophilized polysaccharide. Commercial alginate of known composition and uronic acid distribution, used as standard, was purchased from Sigma.

Acetyl determination. The acetyl content of the EPS was determined according to the procedure of Hestrin (1949). The values obtained were corrected to the actual alginate content of the samples as determined by the Kennedy \& Bradshaw (1984) assay. Acetylcholine was used as standard.

Glucose, fructose and gluconic acid determinations. Fructose and gluconic acid were determined by enzymic assay according to Bergmeyer (1963); D-glucose was assayed using the glucose oxidase/peroxidase reaction modified as a microprocedure (Brivonese, 1986). Enzymes and other reagents were purchased from Sigma or Boehringer.

Alginate lyases. Crude extracellular enzyme preparations were obtained from 4.51 cultures as described by Sutherland \& Macdonald (1986). The preparations were concentrated to $50 \mathrm{ml}$ using a Minitan (Millipore) tangential-flow filtration system with a $10000 M_{\mathrm{r}}$ cut-off membrane and dialysis against polyethylene glycol (PEG) $\left(M_{r} 6000\right)$ at $4{ }^{\circ} \mathrm{C}$, followed by dialysis against distilled water. For the determination of intracellular lyase activity, the cells were harvested by centrifugation, resuspended in $50 \mathrm{mM}$ MES buffer $(\mathrm{pH} \mathrm{7 \cdot 0)}$ and cell extracts were prepared by passing the bacteria through a French pressure cell (Aminco). The resulting cell lysate was ultracentifuged (46000 r.p.m., 2 h), and the supernatant, containing the enzyme fraction, was concentrated by dialysis against PEG and dialysed against distilled water. The final volume was adjusted to $11 \mathrm{ml}$ with $50 \mathrm{mM}$ MES buffer. Different volumes of the enzyme preparations $(20-200 \mu \mathrm{l})$ were added to $500 \mu \mathrm{l}$ of the substrate $(0.5 \%, \mathrm{w} / \mathrm{v}$, alginate in distilled water $)$ plus $50 \mathrm{mM} \mathrm{MES}$, to a final volume of $1 \mathrm{ml}$, and incubated for $16 \mathrm{~h}$ at $30^{\circ} \mathrm{C}$. Lyase activity was measured using the thiobarbituric acid (TBA) assay (Weissbach \& Hurwitz, 1958) on a $100 \mu \mathrm{l}$ sample of the incubation mixture. Bacterial alginate for use as substrate was deacetylated by treatment with $0 \cdot 1 \mathrm{M}$ ammonia at $60^{\circ} \mathrm{C}$ for $30 \mathrm{~min}$, dialysed and lyophilized. The other substrates used were native bacterial alginate and algal alginate of known composition and uronic acid frequency (Kennedy et al., 1992). Protein was measured using a kit from Bio-Rad with bovine serum albumin as standard.

Determination of uronic acid frequencies of alginates. Samples were deacetylated in $0 \cdot 1 \mathrm{M} \mathrm{NaOH}$ for $1 \mathrm{~h}$ at room temperature then samples for NMR analysis were partially depolymerized by mild acid hydrolysis at $\mathrm{pH} 5.0\left(1 \mathrm{~h}, 90^{\circ} \mathrm{C}\right)$ then at pH $3.2\left(1 \mathrm{~h}, 90^{\circ} \mathrm{C}\right)$. The $200 \mathrm{MHz}{ }^{1} \mathrm{H}-\mathrm{NMR}$ spectra were recorded at $90^{\circ} \mathrm{C}$ with a Bruker AC 200 instrument. The monomeric composition and the diad frequencies were determined from the ${ }^{1} \mathrm{H}$ spectra according to the procedure established by Grasdalen et al. (1979).

$\boldsymbol{M}_{\mathbf{r}}$ determination. High-performance size-exclusion chromatography (HPSEC) was performed using a JASCO PV 980 pump equipped with a Rheodyne injector and with a serial set of TSK G 6000 PWXL, G 5000 PWXL and G 3000 PWXL columns (Toso Haas) thermostatted at $40{ }^{\circ} \mathrm{C}$, using a TSK-GEL guard column PWXL. The eluent was $0 \cdot 1 \mathrm{M} \mathrm{NaCl}$ and the flow rate $0.8 \mathrm{ml} \mathrm{min}^{-1}$; detection used a Waters model 410 differential refractometer (DRI). The DRI signal was processed with IBMAT 486 compatible software (ChromStar, Version 3.07, Bruker) for determination of the $M_{\mathrm{r}}$ distribution by means of the socalled 'universal calibration method' (Hamielec, 1984). The calibrations of the HPSEC columns and the peak-broadening correction were performed via a broad standard calibration using alginate samples previously characterized by means of size-exclusion chromatography coupled to a low-angle laser light scattering (LALLS) detector (Martinsen et al., 1991).

\section{RESULTS}

\section{Culture conditions}

Preliminary experiments using basal medium containing $1 \%$ glucose identified the optimum conditions of temperature and agitation for alginate production in shake flasks. Cultures were grown at $25,30,35$ and $37^{\circ} \mathrm{C}$ in volumes of $0.25,0.50,0.75$ and 1.01 in 21 flasks using a 


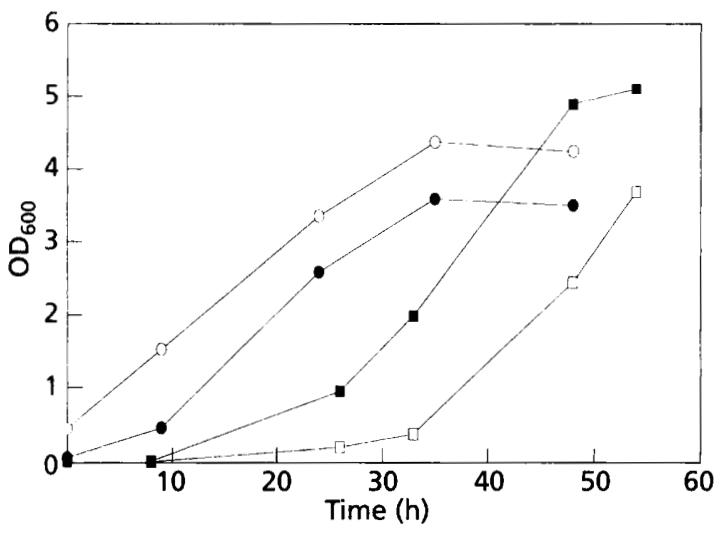

Fig. 1. Growth curves of $P$. putida and $P$. fluorescens in basal medium supplemented with $1 \%$ glucose $(O, P$. putida; $O, P$. fluorescens) or $1 \%$ fructose ( $\square, P$. putida; $\square, P$. fluorescens). Fresh medium $(500 \mathrm{ml}$ in 21 Erlenmeyer flasks) was inoculated with $10 \mathrm{ml}$ overnight cultures of the two strains grown in the presence of either substrate. Growth was then followed at $600 \mathrm{~nm}$.

Table 1. Comparison of cell and EPS yield, and EPS to cell ratio in $P$. putida and $P$. fluorescens after $50 \mathrm{~h}$ growth with fructose or glucose as carbon substrate

\begin{tabular}{|lllll|}
\hline Species & C source & $\begin{array}{c}\text { Cell } \\
\text { yield } \\
\left(\mathrm{g}^{-1}\right)\end{array}$ & $\begin{array}{c}\text { EPS } \\
\left(\mathrm{g}^{-1}\right)\end{array}$ & $\begin{array}{c}\text { EPS/cell } \\
\text { ratio }\end{array}$ \\
\hline P. putida & Glucose & 1.55 & $2 \cdot 2$ & 1.47 \\
P. fluorescens & Glucose & $1 \cdot 4$ & 1.77 & 1.21 \\
P. putida & Fructose & 1.7 & $2 \cdot 2$ & 1.29 \\
P. fuorescens & Fructose & $1 \cdot 0$ & 1.5 & 1.50 \\
\hline
\end{tabular}

reciprocal shaker at 150,180 or 200 r.p.m. Optimal production was obtained in 0.51 medium at $30^{\circ} \mathrm{C}$ and 150 r.p.m. (data not shown) and these conditions were applied for all subsequent studies.

To evaluate the effect of the carbon source on the production and properties of alginate, $P$. putida and $P$. fluorescens cultures were grown in the presence of either glucose or fructose at a concentration of $1 \%$. Overnight cultures were diluted 1:50 in fresh medium and grown for $50 \mathrm{~h}$ or longer under the culture conditions described above. In all the experiments performed it was noted that cultures in the presence of glucose reached the stationary phase before those grown in the presence of fructose. In the latter, growth was characterized by a long lag phase followed by an exponential phase with a growth rate equal to, if not faster than, that of the glucose-grown cultures (Fig. 1). The final cell and EPS yield after about $50 \mathrm{~h}$ growth were comparable in $P$. putida cultures with either substrate. In the case of P. fluorescens, the ratio of EPS to cell yield was slightly higher in the presence of fructose (Table 1). Since fructose-containing cultures of $P$. fuorescens had not reached the stationary phase of growth at the time the experiment was terminated, a further slight increase in EPS production might be expected by prolonging the period of growth.

Substrate utilization and alginate production were followed over a period of $96 \mathrm{~h}$ of growth in P. fluorescens cultured in medium containing glucose or fructose as carbon source. Six cultures were set up for each carbon substrate by inoculating the fresh medium with $10 \mathrm{ml}$ of overnight cultures. Either glucose or fructose was supplied to the cultures at the beginning of growth. After $48 \mathrm{~h}$, a further $1 \%(\mathrm{w} / \mathrm{v})$ of the same substrate was added to three of the six cultures, all of which were then allowed to continue growth for the same time. In the cultures containing only $1 \%$ glucose, the maximum EPS yield was obtained at the end of the exponential phase and it progressively declined on further incubation (Fig. 2a). The addition of the extra glucose at the beginning of the stationary phase resulted in a pulse of growth and maintenance of the alginate level for the rest of the incubation period studied (Fig. 2b). The $\mathrm{pH}$ dropped from $7 \cdot 2$ to $4 \cdot 8$ following addition of the supplementary glucose. A similar pattern of $\mathrm{pH}$ variation was observed when $2 \%$ glucose was supplied at the beginning of growth (data not shown). Although the decrease in $\mathrm{pH}$ might have been due to oxidation of glucose to gluconic acid, enzymic assay procedures failed to show significant amounts of gluconic acid in the fermentation broth. In the presence of $1 \%$ fructose, alginate synthesis continued for an extended period (Fig. $2 \mathrm{~d}$ ). The addition of a further $1 \%$ fructose after $48 \mathrm{~h}$ triggered both growth and alginate synthesis, without significant alteration of $\mathrm{pH}$ (Fig. 2c).

Provided that a sufficiently long incubation time was used, better alginate yield was obtained in the presence of fructose than glucose (Fig. 2). In repeated experiments, maxima of $4.4-4.7 \mathrm{~g}$ alginate $\mathrm{l}^{-1}$ were obtained from $P$. fuorescens cultures grown with fructose as carbon substrate compared with a maximum of $2 \cdot 9 \mathrm{~g} \mathrm{l}^{-1}$ with glucose. In $P$. putida cultures, maximum yields of $3-3.5 \mathrm{~g}$ alginate $\mathrm{l}^{-1}$ were obtained with either substrate.

The nature of the polysaccharide obtained by acetone precipitation from the different culture supernatants varied. The material from $P$. fluorescens cultures with fructose as carbon source formed a large mass which could be recovered from the top of the acetone/water mixture by winding round a glass rod. Similar material was obtained from the $P$. putida cultures, but it rapidly sedimented to the bottom of the flask of the solvent/water mixture, as did the product from most of the cultures of $P$. fluorescens grown with glucose as carbon source. After this material had been lyophilized, it was often difficult to dissolve in water and when in solution it had a high viscosity. In cultures of $P$. fuorescens grown in lownitrogen medium $\left(0 \cdot 1 \% \mathrm{NH}_{4} \mathrm{Cl}\right)$ with $1 \%$ fructose, the product from young cultures resembled that just described. However, older cultures which had been in the stationary phase for some time yielded a much more granular precipitate. Probably the different properties seen during product recovery reflected differences in the physical properties of the polysaccharides. Since the $M_{\mathrm{r}}$ and composition are critical parameters which affect the 


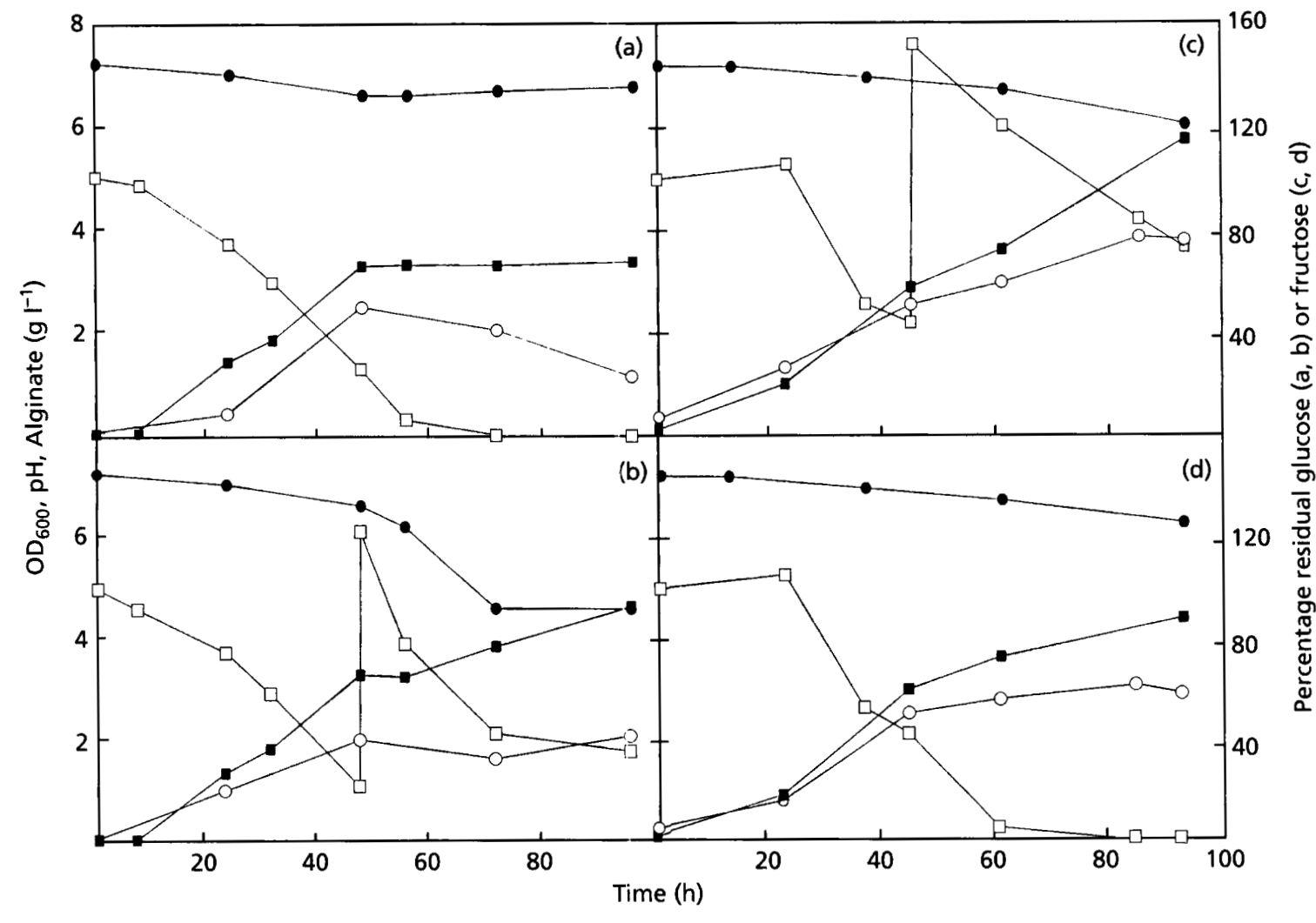

Fig. 2. Growth parameters of $P$. fluorescens in shake flask culture under different conditions. Cells were grown in basal medium supplemented with $1 \%$ glucose $(a, b)$ or $1 \%$ fructose $(c, d)$. In cultures $(b)$ and $(c)$, an additional $1 \%$ glucose or fructose, respectively, was supplied to the cultures after $48 \mathrm{~h}$ growth. Samples $(5 \mathrm{ml})$ of the culture broth were taken aseptically throughout growth to measure the indicated parameters. The concentrations of glucose, fructose and total carbohydrates were determined as indicated in Methods on the supernatant of the samples after centrifugation to remove the cells. Glucose and fructose concentrations are the percentage of residual carbon substrate, with the initial concentration $\left(10 \mathrm{~g} \mathrm{I}^{-1}\right)$ corresponding to $100 \%$. In (a) and (b) the alginate production was estimated by subtracting the glucose concentration from the value for total carbohydrates obtained by the Dubois assay procedure. In (c) and (d) it was determined by the Kennedy \& Bradshaw assay on the supernatant of the samples. The curves are the best fit to the means of triplicate measurements that varied by less than $2 \%$. $\bigcirc$, Alginate production;, $\mathrm{pH} ; \boldsymbol{\square}$, growth; $\square$, residual glucose $(a, b)$ or fructose $(c, d)$.

rheological properties of alginates, further work was done to characterize the polymers obtained.

\section{Nutrient depletion}

Studies on the production of different EPS by bacteria in batch and in continuous cultures have shown that enhanced polysaccharide production may be achieved in cultures under nutritional stress. Magnesium, nitrogen and the carbon substrate were supplied at depleted concentrations in order to assess whether these conditions resulted in improved efficiency of conversion of the carbon substrate into EPS in P. fluorescens. When the content of either magnesium or the carbon substrate was reduced, EPS synthesis and growth were impaired to similar extents. However, when the supply of $\mathrm{NH}_{4} \mathrm{Cl}$ was reduced, the ratio of EPS to cells tended to increase. This effect was particularly apparent in the case of $P$. fluorescens grown in the presence of fructose. These cultures yielded an EPS to cell ratio of 5.3-6.9 at different times of growth in medium with $0.0125 \% \mathrm{NH}_{4} \mathrm{Cl}$ (Table 2). Nevertheless, as EPS production appears to be strictly related to growth, the total EPS yield was substantially lower under these conditions. Surprisingly, the rate of carbon utilization was similar under optimum growth conditions and under conditions which impaired both growth and, to a lesser extent, EPS production (data not shown). The diminished efficiency of conversion of the substrate into both EPS and cell material suggests that under such growth conditions the carbon substrate is channelled into alternative routes, most likely to complete oxidation to carbon dioxide. Thus, while low nitrogen results in a diminished yield of EPS in batch cultures, due to the lower bacterial growth which occurs following early exhaustion of the carbon substrates, it might be the best candidate for limiting growth in continuous cultures.

\section{Characterization of the polymer}

Samples of alginate obtained from both strains at different times of growth, and with either glucose or fructose as the carbon substrates, were analysed by ${ }^{1} \mathrm{H}-\mathrm{NMR}$ to obtain 
Table 2. Effect of nitrogen concentration on EPS and cell yield in $P$. fluorescens cultures at different times of growth with fructose $(1 \%)$ as the carbon substrate

\begin{tabular}{|c|c|c|c|c|c|c|c|c|c|}
\hline \multirow{2}{*}{$\begin{array}{l}\mathrm{NH}_{4} \mathrm{Cl} \\
(\%)\end{array}$} & \multicolumn{3}{|c|}{$48 \mathrm{~h}$} & \multicolumn{3}{|c|}{$72 \mathrm{~h}$} & \multicolumn{3}{|c|}{$96 \mathrm{~h}$} \\
\hline & EPS* & Cell* & EPS/cell & EPS* & Cell* & EPS/cell & EPS* & Cell* & EPS/cell \\
\hline $0 \cdot 20$ & $1 \cdot 40$ & $0 \cdot 84$ & $1 \cdot 75$ & $2 \cdot 90$ & $1 \cdot 10$ & $2 \cdot 64$ & $4 \cdot 10$ & $1 \cdot 38$ & $2 \cdot 97$ \\
\hline $0 \cdot 10$ & $1 \cdot 70$ & 0.92 & $1 \cdot 85$ & $4 \cdot 50$ & $1 \cdot 45$ & $3 \cdot 10$ & $4 \cdot 70$ & $1 \cdot 36$ & $3 \cdot 61$ \\
\hline 0.05 & $1 \cdot 50$ & $0 \cdot 88$ & $1 \cdot 70$ & $2 \cdot 40$ & $1 \cdot 27$ & 1.89 & $3 \cdot 10$ & $1 \cdot 10$ & $2 \cdot 82$ \\
\hline 0.025 & $1 \cdot 40$ & $0 \cdot 23$ & 6.09 & $2 \cdot 00$ & 0.29 & 6.90 & $1 \cdot 85$ & 0.35 & $5 \cdot 28$ \\
\hline
\end{tabular}

* Yields are shown as g lyophilized material $1^{-1}$.

Table 3. Composition and diad frequency of Pseudomonas alginates

\begin{tabular}{|c|c|c|c|c|c|c|c|c|}
\hline Species & $\begin{array}{c}\text { Growth } \\
\text { time } \\
\text { (h) }\end{array}$ & C source & $F_{\mathrm{G}}$ & $F_{M}$ & $F_{\mathrm{MM}}$ & $M_{\mathrm{r}}$ & PI & $\begin{array}{c}\text { Acetyl } \\
\text { content } \\
(\%)\end{array}$ \\
\hline \multirow[t]{2}{*}{ P. putida } & 72 & Glucose & $0 \cdot 22$ & 0.78 & 0.56 & 34000 & $1 \cdot 5$ & 21 \\
\hline & 72 & Fructose & $0 \cdot 22$ & $0 \cdot 78$ & 0.56 & 38500 & $1 \cdot 8$ & 18 \\
\hline \multirow[t]{6}{*}{ P. fluorescens } & 48 & Fructose & $0 \cdot 3$ & $0 \cdot 7$ & $0 \cdot 4$ & 500000 & $1 \cdot 4$ & 12 \\
\hline & 72 & Fructose & $0 \cdot 29$ & $0 \cdot 71$ & 0.42 & 300000 & $1 \cdot 6$ & $17 \cdot 5$ \\
\hline & 96 & Fructose & $0 \cdot 27$ & $0 \cdot 73$ & $0 \cdot 46$ & 176000 & $1 \cdot 6$ & 19 \\
\hline & 48 & Glucose & $0 \cdot 31$ & $0 \cdot 69$ & 0.38 & 276000 & $2 \cdot 1$ & $16 \cdot 9$ \\
\hline & 72 & Glucose & $0 \cdot 35$ & $0 \cdot 65$ & $0 \cdot 3$ & 72000 & $1 \cdot 7$ & $13 \cdot 2$ \\
\hline & 96 & Glucose & $0 \cdot 3$ & $0 \cdot 7$ & $0 \cdot 4$ & 94000 & $1 \cdot 8$ & $16 \cdot 1$ \\
\hline
\end{tabular}

$F_{G}$, frequency of guluronic acid residues; $F_{M}$, frequency of mannuronic acid residues; $F_{M M}$, frequency of adjacent pairs of mannuronic acid residues; PI, polydispersity index.

information about the fractional composition and the nearest-neighbour frequency of mannuronate and guluronate within the polymer. The $M_{\mathrm{r}}$ of the samples was evaluated by gel-permeation chromatography and the acetyl content was also measured. The results are given in Table 3. All samples had a mannuronic to guluronic acid $(\mathrm{M} / \mathrm{G})$ ratio of about $7: 3$. Samples with the highest $M / G$ ratio also exhibited the highest degree of acetylation. The proportion of the various doublet frequencies (M-M or G-G) showed that there was a complete lack of polyguluronic acid sequences; this has also been found for other Pseudomonas alginates (Skjak-Braek et al., 1986). However, monomer composition and degree of acetylation did not seem to be strictly related to the growth phase, nor to either the carbon substrate or the bacterial species. Fairly similar composition in terms of mannuronic acid and guluronic acid was found in samples of different origin. Conversely, the $M_{\mathrm{r}}$ of alginates obtained from different cultures varied widely. Products of low $M_{\mathrm{r}}$ were obtained from $P$. putida cultures, independent of the carbon source used. In P. fuorescens cultures, the alginate produced decreased in $M_{\mathrm{r}}$ with the age of the culture, suggesting that in older cultures either material of lower $M_{\mathrm{r}}$ is produced or, more probably, that degradation of the polymer had occurred. Interestingly, the observed pre- cipitation patterns reflect the $M_{\mathrm{r}}$ of the polymer, with alginate ranging from 276000 to $500000 M_{\mathrm{r}}$ appearing as a large floating mass on acetone precipitation, whereas products of lower $M_{\mathrm{r}}$ settled as a precipitate at the bottom of the flasks. Further evidence for the enzymic degra dation of some of the polysaccharide samples was seen in the observation of a small signal at 5.8 p.p.m. in the proton spectra of these samples due to the $\mathrm{H}-4$ of the unsaturated uronic acid residue generated by the action of a lyase-type enzyme. This signal was especially noticeable in the samples of $P$. putida alginate of lower $M_{\mathrm{r}}$ (Fig. 3a). Solutions of these polysaccharides also displayed high UV absorption at $235 \mathrm{~nm}$, as would be expected for alginates degraded by lyase. In general, the polymers from $P$. fluorescens possessed considerably higher initial $M_{\mathrm{r}}$ which decreased with age of the culture.

\section{Alginate lyase}

Since several bacterial species which synthesize alginatelike polysaccharides also produce alginate-degrading enzymes (e.g. Sengha et al., 1989; Schiller et al., 1993), it was possible that degradation of the polymer by alginate lyases could occur in the older cultures. This would account for the different precipitation patterns and lower 

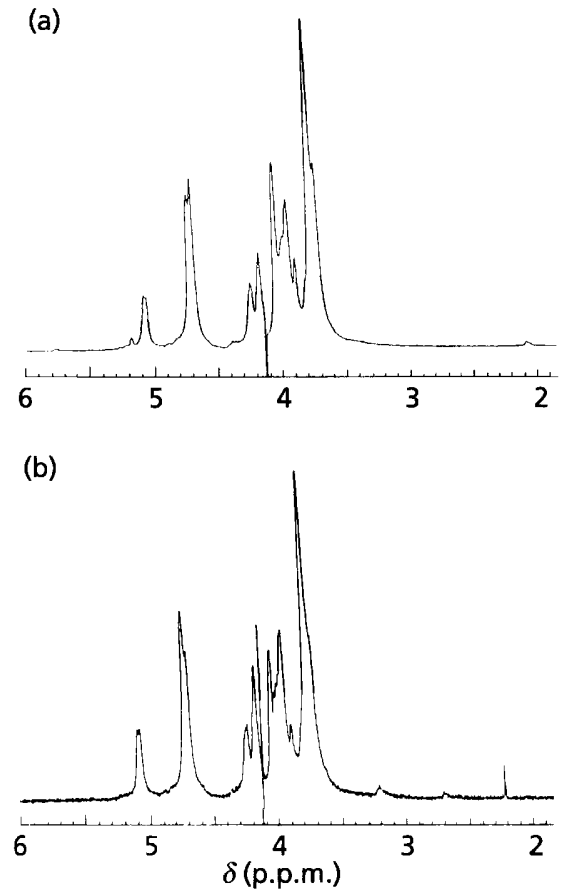

Fig. 3. $200 \mathrm{MHz}{ }^{1} \mathrm{H}-\mathrm{NMR}$ spectra of alginate samples: (a) from $P$. putida cultured in medium with fructose as carbon source, after $72 \mathrm{~h}$ growth; (b) from $P$. fluorescens cultured in medium with fructose as carbon source, after $72 \mathrm{~h}$ growth.

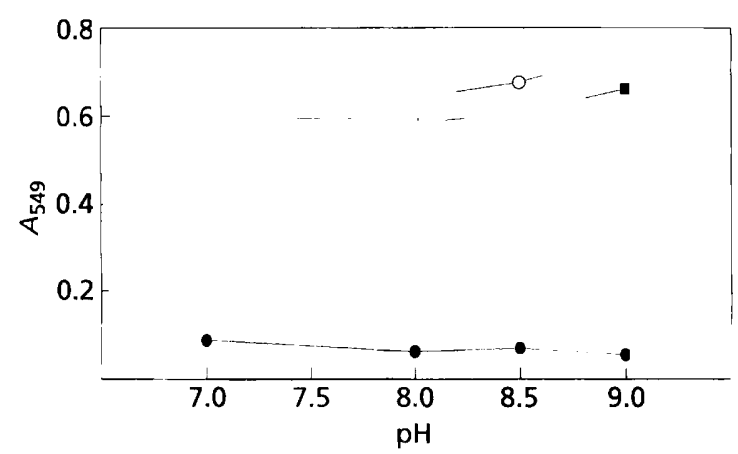

Fig. 4. Activity of the alginate lyase from $P$. fluorescens cultures after $96 \mathrm{~h}$ growth. Crude intracellular enzyme preparation $\left(20 \mu \mathrm{l}, 12.4 \mathrm{mg}\right.$ protein $\left.\mathrm{ml}^{-1}\right)$ was incubated for $16 \mathrm{~h}$ at $30^{\circ} \mathrm{C}$ with different substrates (O, native bacterial alginate; $\square$, deacetylated bacterial alginate; $O$, commercial algal alginate) in buffers at different $\mathrm{pH}$. A negative control was included for each sample, in which the incubation mixture was placed in boiling water for $10 \mathrm{~min}$ to inactivate the enzyme before incubation. The $A_{549}$ values were corrected by subtracting the negative control. The curves are the best fit to the means of triplicate measurements that varied by $1.6 \%$ or less.

$M_{\mathrm{r}}$. Attempts to identify extracellular and intracellular alginate lyase were therefore made using cultures of each of the Pseudomonas species grown for varying periods of time under the different culture conditions used for alginate production. These confirmed that lyase activity was associated with both strains. The results indicated that almost all of the enzymic activity as measured by the TBA reaction was retained intracellularly, independent of the age of the culture (data not shown). Moreover, when various alginate preparations were used, the acetylated bacterial alginates produced by the strains used in the present study proved to be poor substrates for the lyase over a range of $\mathrm{pH}$ values (results for $P$. fuorescens shown in Fig. 4). The relatively high acetyl content $(12-21 \%$, $\mathrm{w} / \mathrm{w}$ ) apparently protected the polymer from the lyase action, whereas the enzymic activity on the chemically deacetylated bacterial alginate was comparable to that found on the commercial algal alginate (Fig. 4). While this observation would minimize the importance of the endogenous enzyme in the degradation of the Pseudomonas polysaccharides, the activity could be sufficient to account for the fall in $M_{\mathrm{r}}$ observed after prolonged incubation of the bacterial cultures.

\section{DISCUSSION}

Studies on the incorporation of specifically labelled sugar substrates into alginate in Azotobacter vinelandii and Pseudomonas putida (Anderson et al., 1987), and in Pseudomonas aeruginosa (Narbad et al., 1988), indicated that, whereas fructose is metabolized as intact hexose units to alginate, glucose is first converted to 6-phosphogluconate and then channelled to the Entner-Doudoroff pathway. Citric acid cycle intermediates are thus the major precursors for alginate biosynthesis from glucose. Furthermore, the cleavage of glucose via gluconate to glyceraldehyde 3-phosphate and pyruvate, and the fact that only glyceraldehyde 3-phosphate is incorporated into alginate, is less efficient and puts the maximum theoretical yield of

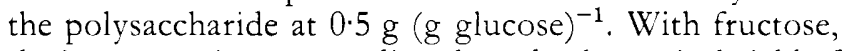
the incorporation occurs directly and a theoretical yield of $100 \%$ (not allowing for cell material) could be expected (Linton, 1990). Anderson et al. (1987) confirmed that for A. vinelandii, alginate yields were almost $20 \%$ lower when the carbon substrate glucose was compared to fructose. However, these workers were unable to compare yields meaningfully for Pseudomonas mendocina as this species secreted a very active alginate lyase which degraded the polymer formed.

Horan et al. (1981) found high yields of alginate synthesized by $A$. vinelandii grown in a phosphate-limited batch culture. From another study on $A$. vinelandii grown in continuous culture (Annison \& Couperwhite, 1986) it emerged that alginates with altered mannuronate/ guluronate ratios could be isolated from cultures grown in medium with different phosphate concentrations. Relatively few studies have reported the effects of different cultural conditions on bacterial alginates from Pseudomonas spp. other than $P$. aeruginosa. Most studies on the physiological effects of growth on polysaccharide production have, however, been concerned with polymers formed of regular repeat units rather than irregular structures such as alginate. Few studies report on the composition and diad frequency of the bacterial alginates, whereas extensive analysis of algal alginates from different species and different parts of the algae have been described 
(e.g. Indergaard \& Skjak-Braek, 1987). However, Sengha et al. (1989) showed that N, C, and O limitations affected both the conversion rate of glucose into alginate and the proportion of mannuronate to guluronate residues in $P$. mendocina. Although manipulation of the culture conditions has thus proved useful in obtaining polymers with altered properties, it should be stressed that other factors, such as the presence of endogenous glycanolytic enzymes, may also affect the characteristics of the final product.

In fructose-grown cultures of the Pseudomonas species studied here, as well as the decrease in $M_{\mathrm{r}}$ there appears to be an increase in acetylation. This is presumably due to the excision of non-acetylated residues by the action of the alginase. The exact specificity of this enzyme has not yet been elucidated but it does appear to differ from most other alginate lyases from Pseudomonas spp. (K. Hughes \& I. W. Sutherland, unpublished results). Alginase production in P. fuorescens and P. putida was also similar to recent reports using $P$. aeruginosa in that alginase was only present in alginate-synthesizing strains. This is thought to be due to the gene for alginate synthesis (algL) forming part of the alg operon (Schiller et al., 1993; Boyd et al., 1993). In all the alginate preparations obtained in this study, D-mannuronic acid is the dominant sugar. This agrees with studies from those other laboratories which have produced detailed analysis of bacterial alginates from Pseudomonas spp. Skjak-Braek et al. (1986) obtained values for the mannuronic acid content of several Pseudomonas alginates ranging from $100 \%$ in a batch preparation from a strain of $P$. aeruginosa to $60 \%$ from a $P$. fluorescens strain. A noticeable difference from our preparations was the very low acetyl content $(3 \%)$ reported by these authors for the latter and the very high content $(37-57 \%)$ for the $P$. aeruginosa polymer. Despite the well-documented differences in derivation of the sugar precursors, we found relatively little dissimilarity in the final analysis of the alginates. All the products analysed from P. fuorescens and $P$. putida showed the same pattern of uronic acid content and of diad frequency. This indicates that, once the precursors have been formed in the intracellular pool, polysaccharide structure is determined by enzymes involved in polymerization, export and epimerization, all of which are presumed to be under strict control in respect of their amount and activity. As the polysaccharide is initially of high $M_{\mathrm{r}}$ and is only subsequently degraded, it also appears unlikely that the alginases of these two Pseudomonas species play a role in polymer synthesis and export as recently suggested by Boyd et al. (1993).

\section{REFERENCES}

Anderson, A. J., Hacking, A. J. \& Dawes, E. A. (1987). Alternative pathways for the biosynthesis of alginate from fructose and glucose in Pseudomonas mendocina and Azotobacter vinelandii. J Gen Microbiol 133, 1045-1052.

Annison, G. \& Couperwhite, I. (1986). Effect of limiting substrate concentration, growth rate and aeration on alginate composition and production by Azotobacter vinelandii in continuous culture. Food Hydrocolloids 1, 101-111.

Bergmeyer, H. U. (1963). Methods of Envymatic Analysis. New York \& W'einheim: Verlag Chemie/Academic Press.
Boyd, A., Ghosh, M., May, T. B., Shinbarger, D., Keogh, R. \& Chakrabarty, A. M. (1993). Sequence of the algL gene of Pseudomonas aeruginosa and purification of its alginate lyase product. Gene 131, 1-8.

Brivonese, A. (1986). Alginate biosyntbesis in Azotobacter vinelandii. $\mathrm{PhD}$ thesis, University of Edinburgh.

Dubois, M., Gilles, K. A., Hamilton, J. K., Rebers, P. A. \& Smith, F. (1956). Colorimetric method for determination of sugars and related substances. Anal Chem 28, 350-356.

Fujihara, M. \& Nagumo, T. (1992). The effect of the content of Dmannuronic acid and L-guluronic acid blocks in alginates on antitumor activity. Carbobydr Res 224, 343-347.

Gacesa, P. \& Goldberg, J. (1992). Heterologous expression of an alginate lyase gene in mucoid and non-mucoid strains of Pseudomonas aeruginosa. J Gen Microbiol 138, 1665-1670.

Gacesa, P. \& Russell, N. J. (1990). Pseudomonas Infections and Alginates. London: Chapman \& Hall.

Garner, C. V., Des Jardins, D. \& Pier, G. B. (1990). Immunogenic properties of Pseudomonas aeruginosa mucoid exopolysaccharide. Infect Immun 58, 1835-1842.

Grasdalen, H., Larsen, B. \& Smidsrod, O. (1979). A n.m.r. study of the composition and sequence of uronate residues in alginates. Carbobydr Res 68, 23-31.

Hamielec, A. E. (1984). Correction for axial dispersion. In Steric Exclusion Liquid Chromatography of Polymers, vol. 25, pp. 117-160. Edited by J. Janca. New York: Marcel Dekker.

Hestrin, S. (1949). The reaction of acetylcholine and other carboxylic acid derivatives with hydroxylamine, and its analytical application. J Biol Chem 180, 249-261.

Horan, N. J., Jarman, T. R. \& Dawes, E. A. (1981). Effects of the carbon source and inorganic phosphate concentration on the production of alginic acid by a mutant of Azotobacter vinelandii and the enzymes involved in its biosynthesis. $J$ Gen Microbiol 127, 185-191.

Indergaard, M. \& Skjak-Braek, G. (1987). Characteristics of alginate from Laminaria digitata cultivated in a high-phosphate environment. Hydrobiologia 151, 541-549.

Kennedy, J. F. \& Bradshaw, I. J. (1984). A rapid method for the assay of alginates in solution using polyhexamethylenebiguanidinium chloride. Br Polymer J 16, 95-101.

Kennedy, L., McDowell, K. \& Sutherland, I. W. (1992). Alginases from Azotobacter species. J Gen Microbio/ 138, 2465-2471.

Lim, F. \& Sun, A. M. (1980). Microencapsulation islets as bioartificial endocrine pancreas. Science 210, 908-910.

Linton, J. D. (1990). The relationship between metabolite production and the growth efficiency of the producing organism. FEMS Microbiol Rev 75, 1-18.

Martin, D. W., Holloway, B. W. \& Deretic, V. (1993). Characterization of a locus determining the mucoid status of Pseudomonas aeruginosa: alg $U$ shows sequence similarities with Bacillus sigma factor. J Bacteriol 175, 1153-1164.

Martins, L. O. \& Sa-Correia, I. (1991). Alginate biosynthesis in mucoid recombinants of Pseudomonas aeruginosa overproducing GDP-mannose dehydrogenase. Enzyme Microb Tecbnol 13, 385-389.

Martinsen, A., Skjak-Braek, G., Smidsrod, O., Zanetti, F. \& Paoletti, S. (1991). Comparison of different methods for determination of molecular weight and molecular weight distribution of alginates. Carbobydr Polym 15, 171-193.

Narbaad, A., Russell, N. J. \& Gacesa, P. (1988). Radiolabelling patterns in alginate of Pseudomonas aeruginosa synthesised from 
specifically-labelled ${ }^{14} \mathrm{C}$-monosaccharide precursors. Microbios $\mathbf{5 4}$, $171-179$

Obika, H., Skakibara, J. \& Kobayashi, Y. (1993). Direct control of the constituents ratio in a wide range in alginate produced by Azotobacter vinelandii. Biosci Biotechnol Biochem 57, 332-333.

Otterlei, M., Ostgaard, K., Skjak-Braek, G., Smidsrod, O., SoonShiong, P. \& Espevik, T. (1991). Induction of cytokine production from human monocytes stimulated with alginate. $J$ Immunother $\mathbf{1 0}$, 286-291.

Schiller, N. L., Monday, S. R., Boyd, C. M., Keen, N. T. \& Ohman, D. E. (1993). Characterization of the Pseudomonas aeruginosa alginate lyase gene $(\operatorname{algL})$ : cloning, sequence and expression in Escherichia coli. J Bacteriol 175, 4780-4789.

Sengha, S. S., Anderson, A. J., Hacking, A. J. \& Dawes, E. A. (1989). The production of alginate by Pseudomonas mendocina in batch and continuous culture. J Gen Microbiol 135, 759-804.

Skjak-Braek, G., Grasdalen, H. \& Larsen, B. (1986). Monomer sequence and acetylation pattern in some bacterial alginates. Carbobydr Res 154, 239-250.

Sutherland, I. W. (1987). Polysaccharide modification - a physiological approach. In Industrial Polysaccharides: Genetic Engineering, Structure/Properties Relations and Applications, pp. 71-79. Edited by M. Yalpani. Amsterdam: Elsevier Science Publishers.

Sutherland, I. W. (1991). Alginates. In Biomaterials, pp. 307-331. Edited by D. Byrom. New York: Macmillan.

Sutherland, I. W. \& Macdonald, R. M. (1986). Extracellular enzyme isolation and purification from exopolysaccharide-producing bacteria. J Microbiol Metbods 6, 27-31.

Weissbach, A. \& Hurwitz, J. (1958). The formation of 2-keto-3deoxyheptonic acid in extracts of Escherichia coli. J Biol Chem 234, 705-709.

Received 11 August 1993; accepted 22 November 1993. 